\title{
A MODIFICATION OF GRAVES' OPERATION FOR EPIPHORA DUE TO STENOSIS OF THE LACRIMAL PUNCTUM*
}

\author{
BY
}

\section{J. B. TREVELYAN THOMAS}

Bournemouth

SEVERAL years ago a description was published of a new technique in performing the three-snip operation to relieve epiphora due to stenosis of the lacrimal punctum (Graves, 1926). The method was to dilate the punctum, insert a small grooved director, place the back of a large Ziegler knife in the groove, and then, by pushing it inwards towards the nose, to incise the upper edge of the canaliculus to any required extent. The result was to produce a small triangular flap, with its apex below. The base was seized by forceps, and removed in two or three snips with small scissors.

As Mr. Basil Graves correctly pointed out in his article, this little operation did not destroy the capilliary action of the canaliculus, as did the older operation of slitting through the entire length of the canaliculus, with a canaliculus knife.

I have recently adopted a modification of Graves' method, suggested to me by my colleague, Mr. David Hardie of Bournemouth:

The instruments required are:
(1) canaliculus dilator;
(2) small pointed scissors;
(3) small straight iris forceps.

Anaesthesia is obtained with local infiltration in the region of the lower canaliculus, and cocaine drops.

After dilating the punctum, one point of a fine scissors is inserted into the punctum with the cutting edge upwards, and with one or two snips, the upper limit of the flap is quickly made. The flap is then removed as in Graves' operation.

This operation is extremely simple, and one can enlist the help of the patient to pull the lid down, which gives him a personal interest in the operation, and relieves some of the nervous tension.

\section{REFERENCE}

Graves, B. (1926). Amer. J. Ophthal., 9, 675.

*Received for publication February 13, 1951. 